\title{
Osteoporosis and type 2 diabetes
}

Authors: D.Meskine, A.Bouzid

Laboratoire d'Endocrinologie et Métabolisme (LEM) Alger-1, Alger, ALGÉRIE

\section{Objectives:}

Diabetes mellitus and osteoporosis are important comorbidities commonly seen in postmenopausal women. Diabetes can cause bone alterations that increases the risk of fractures. However, in patients with type 2 diabetes, bone mineral density (BMD) often appears not to be decreased, due to diabetes-induced increased weight and body fat mass, which can hamper densitometric assessment of osteoporosis and of fracture risks. The aim of the present study was to compare bone mineral density (BMD) in two samples of postmenopausal women with and without type 2 diabetes

\section{Methods:}

This was a cross-section study conducted at the Bologhine Hospital of Algiers (Algeria). The study group consisted of 195 women with type 2 diabetes, recruited from an original sample of 1062 patients (age $>45$ years) who were screened for osteoporosis in postmenopausal women. Subject were grouped as diabetic and non diabetic. A questionnaire containing factors reported to affect BMD was filled for all subjects.

Weight and height were measured by standard methods, BMI was calculated using the formula [Weight $(\mathrm{kg})$ divided by square height(square meter)] BMD was assessed by Dual Energy X-ray Absorptiometry technique Lumbar spine and femoral neck BMD and other relevant clinical data were compared to those of a control group $(n=867)$ comprising the women who did not have diabetes.
Table 1: Baseline characterictics of the different variables in postmenopausal diabetic and non diabetic women

\begin{tabular}{|l|c|c|c|}
\hline Variable & $\begin{array}{c}\text { Non diabetic women } \\
(\mathbf{n}=\mathbf{8 6 7})\end{array}$ & $\begin{array}{c}\text { Diabetic women } \\
(\mathbf{n}=\mathbf{1 9 5})\end{array}$ & P value \\
\hline age(year) & $60.6(8.4)$ & $63.2(8.4)$ & $<0.001$ \\
\hline Mean(SD) & $72.5(13.1)$ & $75.6(14.1)$ & 0.003 \\
\hline Weight(kg) & $157.3(5.8)$ & $156.8(6.6)$ & 0.229 \\
\hline Height(cm) & $29.3(4.9)$ & $30.7(5.3)$ & $<0.001$ \\
\hline BMI(kg/m²) & $13.5(1.6)$ & $13.4(1.6)$ & 0.324 \\
\hline Age of menarche & $12(9.1)$ & $14.7(10.1)$ & $<0.001$ \\
\hline $\begin{array}{l}\text { Duration of } \\
\text { menopause }\end{array}$ & & &
\end{tabular}

Table 2: Bone density in postmenopausal diabetic and non diabetic women

\begin{tabular}{|l|c|c|c|}
\hline Variable & $\begin{array}{c}\text { Non diabetic women } \\
(\mathbf{n}=\mathbf{8 6 7})\end{array}$ & $\begin{array}{c}\text { Diabetic women } \\
(\mathbf{n}=\mathbf{1 9 5})\end{array}$ & $\mathbf{P}$ value \\
\hline BMD of hip & $0,8 \pm 01$ & $0,8 \pm 01$ & 0.271 \\
\hline BMD of femoral neck & $0,7 \pm 01$ & $0,7 \pm 01$ & 0,81 \\
\hline BMD of spine & $0,9 \pm 01$ & $0,8 \pm 01$ & 0,019 \\
\end{tabular}

\section{Results:}

Women with type 2 diabetes had significantly higher mean lumbar spine BMD $(0.9 \pm 0.1 \mathrm{vs.} 0.8 \pm 0.1$, respectively, $P<0.019)$ than nondiabetic women. But no difference in mean femoral neck BMD $(0.7 \pm 0.1$ vs. $0.7 \pm 0.1$, respectively, $P: 0,81)$ was observed. The proportion of osteoporotic women was $27.7 \%$ in the group of women with type 2 diabetes, vs. $29.8 \%$ in the control group.

\section{Conclusion:}

The association between diabetes mellitus and osteoporosis remains controversial. The degree of bone loss differs between type 1 and type 2 diabetes. In some studies, type 2 diabetes has been associated with an increase in bone mineral density.

Our findings support those of other studies that found higher BMD in patients with type 2 diabetes compared to the general population.

\section{References:}

1) Wongdee $K$, Charoenphandhu N. Osteoporosis in diabetes mellitus : Possible cellular and molecular mechanisms. World J Diabetes 2011;2:418

2) Hofbauer LC, Brueck CC, Singh SK, Dobnig H. Osteoporosis in patients with diabetes mellitus. J Bone Miner Res 2007;22:1317-28 3) Erin Gorman, Anna M.Chudyk, Kenneth M.Madden, Maureen C.Ashe. Bone health and type 2 Diabetes Mellitus: A Systematic Review. Physiother Can. 2011 